\title{
Relationship between ROS production, MnSOD activation and periods of fasting and re-feeding in freshwater shrimp Neocaridina davidi (Crustacea, Malacostraca)
}

\author{
Agnieszka Włodarczyk ${ }^{1}$, Grażyna Wilczek ${ }^{2}{ }$, Piotr Wilczek $^{3}{ }^{3}$, Sebastian Student ${ }^{4}$, Anna Ostróżka $^{1}$, Monika \\ Tarnawska $^{2}$, Magdalena Rost-Roszkowska ${ }^{\text {Corresp. } 1}$ \\ 1 Department of Animal Histology and Embryology, University of Silesia in Katowice, Katowice, Poland \\ 2 Department of Animal Physiology and Ecotoxicology, University of Silesia in Katowice, Katowice, Poland \\ 3 Bioengineering Laboratory, Heart Prosthesis Institute, Zabrze, Poland \\ 4 Faculty of Automatic Control, Silesian University of Technology, Gliwice, Poland \\ Corresponding Author: Magdalena Rost-Roszkowska \\ Email address: magdalena.rost-roszkowska@us.edu.pl
}

The middle region of the digestive system, the midgut of freshwater shrimp Neocaridina davidi is composed of a tube-shaped intestine and the hepatopancreas formed by numerous caeca. Two types of cells have been distinguished in the intestine, the digestive cells (D-cells) and regenerative cells (R-cells). The hepatopancreatic tubules have three distinct zones distinguished along the length of each tubule - the distal zone with R-cells, the medial zone with differentiating cells, and the proximal zone with F-cells (fibrillar cells) and B-cells (storage cells). Fasting causes activation of cell death, a reduction in the amount of reserve material, and changes in the mitochondrial membrane potential. However, here we present how the concentration of ROS changes according to different periods of fasting and whether re-feeding causes their decrease. In addition, the activation/deactivation of mitochondrial superoxide dismutase (MnSOD) was analyzed. The freshwater shrimps Neocaridina davidi (Crustacea, Malacostraca, Decapoda) were divided into experimental groups: animals starved for 14 days, animals re-fed for 4, 7, and 14 days. The material was examined using the confocal microscope and the flow cytometry. Our studies have shown that long-term starvation increases the concentration of free radicals and MnSOD concentration in the intestine and hepatopancreas, while return to feeding causes their decrease in both organs examined. Therefore, we concluded that a distinct relationship between MnSOD concentration, ROS activation, cell death activation and changes in the mitochondrial membrane potential occurred. 
1 Relationship between ROS production, MnSOD activation and periods of

2 fasting and re-feeding in freshwater shrimp Neocaridina davidi (Crustacea,

5 Włodarczyk A. ${ }^{1}$, Wilczek G. ${ }^{2}$, Wilczek P. ${ }^{3}$, Student S. ${ }^{4}$, Ostróżka A. ${ }^{1}$, Tarnawska M. ${ }^{2}$, Rost-

81 University of Silesia in Katowice, Department of Animal Histology and Embryology, 9 Katowice, Poland

102 University of Silesia in Katowice, Department of Animal Physiology and Ecotoxicology,

11 Katowice, Poland

$12{ }^{3}$ Heart Prosthesis Institute, Bioengineering Laboratory, Zabrze, Poland

$13{ }^{4}$ Faculty of Automatic Control, Electronics and Computer Science, Silesian University of 14 Technology, Gliwice, Poland

19 Magdalena Rost-Roszkowska,

Department of Animal Histology and Embryology, University of Silesia in Katowice, Bankowa *email: magdalena.rost-roszkowska@us.edu.pl 


\section{Abstract}

27 The middle region of the digestive system, the midgut of freshwater shrimp Neocaridina davidi is composed of a tube-shaped intestine and the hepatopancreas formed by numerous caeca. Two types of cells have been distinguished in the intestine, the digestive cells (D-cells) and regenerative cells (R-cells). The hepatopancreatic tubules have three distinct zones distinguished along the length of each tubule - the distal zone with R-cells, the medial zone with differentiating cells, and the proximal zone with F-cells (fibrillar cells) and B-cells (storage cells). Fasting causes activation of cell death, a reduction in the amount of reserve material, and changes in the mitochondrial membrane potential. However, here we present how the concentration of ROS changes according to different periods of fasting and whether re-feeding causes their decrease. In addition, the activation/deactivation of mitochondrial superoxide dismutase (MnSOD) was analyzed. The freshwater shrimps Neocaridina davidi (Crustacea, Malacostraca, Decapoda) were divided into experimental groups: animals starved for 14 days, animals re-fed for 4, 7, and 14 days. The material was examined using the confocal microscope and the flow cytometry. Our studies have shown that long-term starvation increases the concentration of free radicals and MnSOD concentration in the intestine and hepatopancreas, while return to feeding causes their decrease in both organs examined. Therefore, we concluded that a distinct relationship between MnSOD concentration, ROS activation, cell death activation and changes in the mitochondrial membrane potential occurred.

Key words: digestive system, midgut, epithelium, starvation, free radicals 
49

50

51

52

53

54

55

56

57

58

59

60

61

62

63

64

65

66

67

68

69

70

71

\section{Introduction}

An animal organ which is exposed to various stressors originating from the environment is the midgut (the middle region of the digestive system). It takes part in maintenance of homeostasis of the entire organism. In nature, organisms can be exposed to periodic lack of food or various external harmful stressors, and as a result have evolved mechanisms that help animals to survive in adverse environmental conditions. The midgut is the main place of accumulation of reserve material in invertebrates, which may be used during starvation (Cervellione et al., 2017). Therefore the processes related to the survival strategy during exposure to starvation are observed primarily in this organ. Long-term periods of starvation can cause numerous changes at the physiological, biochemical and molecular levels which lead to increased ability to survive (Wilczek et al., 2014; Lipovšek et al., 2015, 2018; Lipovšek and Novak, 2015; Włodarczyk et al., 2017, 2019). Starvation can affect and damage many organelles, including the mitochondria (Ratcliffe and King, 1969; Włodarczyk et al., 2017), which are responsible for e.g. synthesis of ATP and reactive oxygen species (ROS), or activation of cell death (Martin, 2010; Kamogashira et al., 2015; Włodarczyk et al., 2019). Ultrastructural alterations of mitochondria (FernandezCheca, 2003; Faron et al., 2015; Włodarczyk et al., 2017) also cause changes in the functioning of the enzyme system. In several places along the mitochondrial respiratory chain (mainly due to complexes I and III), electrons can react directly with oxygen or another electron acceptor and generate free radicals. As a result, the superoxide anion radical $\left(\mathrm{O}_{2^{-}}\right)$, hydroxide ions $\left(\mathrm{OH}^{-}\right)$, and hydrogen peroxide $\left(\mathrm{H}_{2} \mathrm{O}_{2}\right)$ are formed. They must be eliminated by activation of the precise enzymatic system (Cadenas and Davies, 2000; Ramalho-Santos et al., 2009; Yao et al. 2004, 2007; Hung et al., 2014). Among the antioxidant enzymes, the superoxide dismutases (SOD) play protective roles against the effect of free radicals on organelles, e.g. mitochondria (Zelko et 
72 al., 2002; Zhang et al. 2007; Combelles et al., 2009; Umasuthan et al. 2012; Faron et al., 2015).

73 Based on associated metal cofactors, four classes of SOD have been distinguished: $\mathrm{Cu} / \mathrm{ZnSOD}$,

MnSOD, FeSOD and NiSOD (Fridovich, 1995; Zelko et al., 2002). However, the Cu/ZnSOD commonly present in vertebrates has been replaced by MnSOD in crustaceans that is connected with the transport of oxygen by copper from haemocyanin (Brouwer et al., 2003). Two types of this enzyme can be recognized: cytMnSOD and mtMnSOD. mtMnSOD has been described as commonly distributed in animals, plants and bacteria, while cytMnSOD has been found only in Crustacea such as prawns, crabs, lobsters, and shrimps (Brouwer et al., 2003; Lin et al. 2010; Gomez-Anduro et al., 2012). ectodermal fore- and hindgut, while the endodermal midgut can be differentiated into intestine and hepatopancreas (Herrera-Alvarez et al., 2000; Sousa and Petriella, 2006; Sonakowska et al., 2015; Sacristán et al., 2014, 2016; Cervellione et al., 2017). Many studies have been conducted on crustaceans that have been starved, but they mainly concern the physiological alterations in organisms and they were conducted on species that are adapted to short-term periods of starvation, connected with e.g. molting or to long-term starvation (Sacristán et al., 2016). However, our previous studies on freshwater shrimp Neocaridina davidi (formerly Neocaridina heteropoda) were focused on long-term starvation. This species originates from Taiwan and it gained its popularity thanks to ease of breeding. In addition, its natural environment and feeding habitats resemble those observed in the majority of freshwater crustaceans all over the world. The midgut of $N$. davidi is composed of a tube-shaped intestine and the hepatopancreas formed by numerous caeca (Sonakowska et al., 2015). Two types of cells have been distinguished in the intestine, the digestive cells (D-cells) and regenerative cells (R-cells), while the structure of the 
95 hepatopancreas is more complicated. It is formed by numerous tubules with three distinct zones

96 distinguished along the length of each tubule - the distal zone with R-cells, the medial zone with

97 differentiating cells, and the proximal zone with F-cells (fibrillar cells) and B-cells (storage cells)

98 (Sonakowska et al., 2015, 2016). The impact of fasting and re-feeding on ultrastructural changes

99 and activation of cell death in the midgut epithelium of this species has also been described

100 (Włodarczyk et al., 2017, 2019). Fasting causes activation of cell death, a reduction in the

101 amount of reserve material, and changes in the mitochondrial membrane potential. These

102 alterations are probably the mechanisms which enable an animal to survive. However, re-feeding

103 reverses all these changes (Włodarczyk et al., 2017, 2019). In order to gain a full view of the

104 described changes, we decided to investigate how the concentration of ROS changes according

105 to different periods of fasting and, what is the most important, whether re-feeding causes their

106 decrease. In addition, the activation/deactivation of one of the stress-responsive factor important

107 in antioxidative processes - mitochondrial superoxide dismutase (MnSOD) - was analyzed.

108

109 Material \& Methods

\section{Materials}

111 The research was conducted on adult specimens of the freshwater shrimp Neocaridina

112 davidi (formerly named as N. heteropoda) (Crustacea, Malacostraca, Decapoda). The specimens

113 were obtained from local shrimp breeders and kept in a laboratory breeding facility, i.e. a 40 L

114 shrimp tank equipped with heater with thermostat and mechanical filtration system. The water

115 temperature was set to $21^{\circ} \mathrm{C}, \mathrm{pH}$ to 7 and total water hardness was $10^{\circ} \mathrm{d}$. The $N$. davidi shrimps

116 were fed with JBL Novo Prawn. For the experiment, adult shrimps with cephalothorax length 
117 over $2.5 \mathrm{~mm}$ were chosen. The specimens were in good condition, actively moving and taking in

118 food. To collect the material no specific permissions were required for locations/activities.

120 Experiment. The fasting experiment was performed by placing shrimps in isolated plastic (250

$121 \mathrm{~mL}$ ) containers. Every day $10 \%$ of the water amount was replaced and the plastic containers

122 were cleaned of excrements. Containers were kept in a shaded room to avoid development of 123 algae. Shrimps were starved for 14 days. Specimens were collected for studies. Additionally, 124 some specimens from the experimental group were re-fed for 4, 7, and 14 days. The periods of 125 starvation and re-feeding were established according to our previous experiments and the results 126 obtained (Włodarczyk et al., 2017, 2019). The number of specimens from the experimental group 127 that were collected for the experiment and all techniques used are presented in Table 1. 128 Individuals of $N$. davidi were slightly anesthetized on ice and midguts were dissected.

Methods

\section{Confocal microscopy}

Dihydroethidium (DHE) - a dye commonly used to evaluate reactive oxygen species (ROS)

production, which penetrates all cell membranes. Isolated organs, without fixation, were washed in PBS (phosphate-buffered saline) with $0.0025 \%$ Triton X100 (RT) and stained with $30 \mu \mathrm{M}$ DHE (Invitrogen) prepared from the $30 \mathrm{mM}$ stock solution of DHE in DMSO. Tissues were incubated with the dye for 15 minutes in a dark chamber, at room temperature. After washing the material with PBS, it was labeled with DAPI (30 min in darkness). The material was analyzed with an Olympus FluoView FV1000 confocal microscope. 
141 Superoxide dismutase (SOD) detection - one of the primary antioxidant enzymes: increased

142 MnSOD protects normal tissue against oxidative stress. MnSOD as one of the SOD enzymes is a

143 critical antioxidant enzyme residing in mitochondria. The isolated organs (intestine and

144 hepatopancreas) were fixed in Karnovsky fixative $\left(2 \mathrm{~h}, 4{ }^{\circ} \mathrm{C}\right)$ and then permeabilized in

$145 \mathrm{PBS} / 0.1 \% \mathrm{v} / \mathrm{v}$ Triton $\mathrm{X}-100 \mathrm{pH} 7.4$ for $5 \mathrm{~min}$ at room temperature. In addition, tissues were

146 blocked in PBS/5\% w/v BSA pH 7.4 for 20 min and stained with primary antibody: anti-MnSOD

147 rabbit polyclonal antibody (1:500; Stressgen) overnight at room temperature. Tissues were

148 washed with PBS ( $\mathrm{pH}$ 7.4) and incubated with goat anti-rabbit IgG secondary antibody

149 conjugated with Alexa Fluor 488 (1:1000, Invitrogen). After washing the material with PBS, it

150 was labeled with DAPI (30 min in darkness). The slides were analyzed with an Olympus

151 FluoView FV1000 confocal microscope.

152

153 Sample preparation for Western blot analysis

154 Individuals of $N$. davidi from the control group were slightly anesthetized on ice and midguts

155 were dissected ( 5 per sample). The midguts were then homogenized on ice in TBS buffer (Tris-

156 buffered saline). Homogenates were then centrifuged at $4{ }^{\circ} \mathrm{C}, 15000 \mathrm{~g}$ for $10 \mathrm{~min}$. In the

157 supernatants, total protein concentration was measured (Bradford, 1976) and detection of 158 superoxide dismutase (MnSOD) was performed.

159

160

Western blot analysis

161 Denatured samples (water bath, $\left.5 \mathrm{~min}, 95^{\circ} \mathrm{C}\right)$ of identical amounts of protein $(25 \mu \mathrm{g})$ were

162 loaded and separated by $10 \%$ SDS-PAGE (30 min at $90 \mathrm{~V}$, then $1 \mathrm{~h}$ at $120 \mathrm{~V})$ and then

163 transferred to the nitrocellulose membrane (Optitran BA-S 85, Whatman) with Mini Transfer- 
164 Blot (BIO-RAD) (2 h at $150 \mathrm{~V}, 300 \mathrm{~mA})$. Next, the membranes were blocked (3\% bovine serum 165 albumin (BSA) in Tris-buffered saline (TBS), $1 \mathrm{~h}$, at room temperature (RT)). Blots were 166 incubated with specific primary antibody: anti-superoxide dismutase (MnSOD) developed in 167 rabbit (Sigma) (overnight, at $4{ }^{\circ} \mathrm{C}$, with continuous shaking). After incubation, the membranes 168 were washed four times for $5 \mathrm{~min}$ in TBS with $0.1 \%$ Tween-20 (TBST) and then incubated with 169 secondary antibody: Goat anti-rabbit IgG, AP conjugate (Enzo Life Sciences) (1h, at RT, 170 continuously shaking). Dilutions of the antibodies were conducted following the manufacturer's 171 instructions, in 1\% BSA in TBS. After washing ( 4 x 5 min in TBST), the antibody complex was 172 visualized by BCIP/NBT Solution (BioShop), washed again in distilled water, dried, and 173 scanned.

\section{Total protein concentration}

176 Total protein concentration was measured according to the Bradford method (1976). The method 177 is based on the binding of aromatic amino acids to the Coomassie Brilliant Blue (CBB, G-250, 178 Sigma) dye with the v/v 1 (sample): 50 (CBB solution) ratio. The absorbance was measured at 179 the wavelength of $595 \mathrm{~nm}$, and the color intensity is proportional to protein concentration. The protein concentration was calculated from the calibration curve prepared from the absorbance measurements of the bovine serum albumin (protein content $>95 \%$, Sigma) solutions of known concentrations (Bradford, 1976).

\section{Flow cytometry}

186 The dissected organs isolated from specimens from each experimental group were mechanically 187 fragmented with scissors and suspended in $100 \mu \mathrm{L}$ of PBS (pH 7.4). Then, the intestine and 
188 hepatopancreas cells were separated by gentle shaking in a homogenizer (Minilys, Bertin 189 Technologies). The cell suspension was washed using centrifugation at $1500 \mathrm{rpm}$ for five 190 minutes and the precipitate was suspended in $100 \mu \mathrm{L}$ of PBS buffer.

191 For the quantitative measurements of cellular populations undergoing oxidative stress 192 were used the Muse Oxidative Stress Kit (Merck Millipore, № MCH100111). The assay is based 193 on dihydroethidium (DHE), which upon reaction with superoxide anions undergoes oxidation, 194 resulting in red fluorescence. According to the manufacturer's protocol, the results were 195 expressed as the percentage of two populations of cells: ROS negative (live cells) and ROS 196 positive (cells exhibiting ROS). The measurements were performed using the Beckman Coulter 197 Instrument FC 500 flow cytometer with a $488 \mathrm{~nm}$ argon laser.

Statistical analysis

200 Statistical analyses were performed using the STATISTICA 10.0 software package (StatSoft, 201 Inc. (2010) version 10.0. http://www.statsoft.com). Normality was checked using the Shapiro202 Wilk test. The data were tested for homogeneity of variance using Levene's test of equality of 203 error variances. The significance of the differences in the percentage of ROS positivity between 204 organs within the complementary groups was assessed using Student's t-test, $p<0.05$. The 205 significance of differences in the percentage of ROS positivity among different time periods of 206 starvation and re-feeding after starvation within each organ was assessed using the Tukey test, $207 p<0.05$. All assays were based on 5-6 samples, performed in duplicate.

208

209 Results 
210 Our previous studies have shown that there are no differences in the structure and changes in the 211 intestinal epithelium of females and males (Włodarczyk et al., 2017, 2018). Therefore, these 212 studies represent the results with the omission of $N$. davidi sexes. The use of dihydroethidine 213 (DHE) for $N$. davidi intestine and hepatopancreas revealed a diverse distribution of ROS in all 214 experimental groups. A weak signal was seen in some of the cells in both organs in the control 215 group (Figs. 1A-B). The quantitative analysis showed $2.8 \% \pm 1.2$ and $1.3 \% \pm 0.6$ ROS-positive 216 cells in the hepatopancreas and intestine respectively (Table 2). After 14 days of starvation the 217 percentage of ROS-positive cells strongly increased: $13.2 \% \pm 2.1$ in the hepatopancreas and $12.7 \% \pm 1.2$ in the intestine (Table 2 ). The qualitative analysis confirmed this, showing strong signals in both organs examined (Figs. 1C-D). Re-feeding for 4 days after 14 days of starvation caused an increase in the number of ROS-positive cells in the hepatopancreas $15.7 \% \pm 4.4$, while in the intestine their number decreased to $(9.2 \% \pm 4.3)$ in comparison to animals starved for 14 days (Table 2). The signals from hepatopancreatic cells were stronger, whereas signals from intestinal cells were weaker according to the previous experimental group (Figs. 1E-F). However, 7 days of re-feeding after starvation caused a strong decrease in the number of ROSpositive cells in both organs analyzed $-5.4 \% \pm 1.8$ (hepatopancreas) and $2.0 \% \pm 0.4$ (intestine) (Table 2) - which was confirmed by the weak signals from epithelial cells in both organs (Figs. 1G-H). Epithelial cells in hepatopancreas and intestine isolated from animals starved for 14 days and re-fed for 14 days also emitted weak signals (Figs. 2A-B). The quantitative analysis showed that the number of ROS-positive cells in the hepatopancreas decreased in comparison to animals re-fed for 7 days $(4.2 \% \pm 0.6)$, while it was the same in the intestine: $2.0 \% \pm 0.4$ (Fig. 3) (Table 2). The immunofluorescent method for detecting superoxide dismutase (MnSOD) at the level 
233 cells in the control specimens of $N$. davidi. The specificity of the antibodies was confirmed by

234 Western blot technique (Fig. 4). The mitochondria of the epithelial cells in both organs in 235 animals starved for 14 days expressed a higher amount of MnSOD in comparison to the control 236 group. The longer the animals were re-fed after 14 days of starvation, the weaker were the 237 signals emitted by epithelial cells in the hepatopancreas and intestine (Figs. 5A-H, 6A-B).

\section{Discussion}

In recent years, intensive studies connected with the response of organisms to the stress of starvation/fasting in invertebrates have been carried out. In the studied invertebrate species, the authors described the susceptibility to starving and changes at the ultrastructural level in the epithelium of the digestive system (Wilczek et al., 2014; Lipov̌̌ek et al., 2015, 2018; Lipovšek and Novak, 2015; Rost-Roszkowska et al., 2018), including crustaceans (Cervellione et al., 2017; Pantãleo et al., 2015; Sacristán et al., 2014, 2016; Włodarczyk, 2017, 2019). Ultrastructural changes may be associated with an increase in the concentration of free radicals in the examined cells (Kaminskyy and Zhivotovsky, 2014; Chen et al., 2009; Redza-Dutordoir et al., 2016). Free radicals could derive either from numerous essential enzymatic and nonenzymatic reactions or can be caused by external stressors such as xenobiotics, X-rays, pathogens or even periods of starvation. Hence, the animals developed numerous defense mechanisms which participate in homeostasis maintenance. One of them is the production of antioxidants such as superoxide dismutases, catalase, glutathione, thioredoxin, etc. (Borković et al., 2008; Ighodaro and Akinloye, 2018; Mailloux, 2018). When the balance between free radical generation and antioxidant defenses is disturbed, oxidative stress occurs (Bagchi and Puri, 1998; Combelles et 
256 enzymatic mechanisms are involved in the response to stressful conditions in crustaceans.

257 Mainly two enzymes, catalase and superoxide dismutase (SOD), are treated in these aquatic

258 invertebrates as the major indicators of oxidative stress (Borković et al., 2008; Mohana et al.,

259 2016, Soberanes-Yepiz et al., 2018). The level of lipids and proteins in animals' diet has an effect

260 on the course of antioxidative processes (Zenteno-Savin et al. 2008, Goda, 2008, ; Sacristán et

261 al., 2016; Méndez-Martínez et al., 2018; Soberanes-Yepiz et al., 2018). Starved crayfish showed

262 alterations in level of lipids, glycogen, and glutathione, but fasting did not affect the level of

263 catalase, protein oxidation or activity of some enzymes. Long-term starvation also causes a

264 decrease in the number of molts in crustaceans, suggesting that they do not adapt to long periods

265 of fasting (Sacristán et al., 2016). The effect of diet on the activation of defense mechanisms

266 against oxidative stress has been presented for e.g. Macrobrachium americanum (Soberanes-

267 Yepiz et al., 2018), M. rosembergii (Mohana et al., 2016), Penaeus monodon

268 (Sivagnanavelmurugan et al., 2014) and Cherax quadricarinatus (Sacristán et al., 2016). The

269 transport of oxygen by copper from haemocyanin in crustaceans caused that $\mathrm{Cu} / \mathrm{ZnSOD}$ has been

270 replaced by MnSOD (Brouwer et al., 2003). Additionally, in these aquatic arthropods two types

271 of this enzyme have been described: cytMnSOD and mtMnSOD. While mtMnSOD is commonly

272 distributed in crustaceans as in the other animals, cytMnSOD has been only found in many

273 species of prawns, crabs, lobsters, shrimps (Brouwer et al., 2003; Lin et al. 2010; Gomez-Anduro

274 et al., 2006, 2012; Zhao et al., 2014; Soberanes-Yepiz et al., 2018). Total MnSOD in crustaceans

275 is treated not only as a defense response against fasting, but also as an important factor in the

276 immune responses against pathogen infections (Zhang et al., 2007, Yu et al., 2011), metal

277 exposure (Haque et al., 2018) and even water pollution and ozonization (Oropesa et al., 2017).

278 The relationship between oxidative stress and total MnSOD activation as the effect of starvation 
279 has also been described in starved specimens of $N$. davidi. Under the influence of two-week

280 fasting, an increase in the concentration of free radicals from $2.8 \%$ and $1.3 \%$ to $13.2 \%$ and

$28112.7 \%$ (for the hepatopancreas and the intestine, respectively) and an increase in antioxidant

282 (MnSOD) production were observed. In this study, the change in total MnSOD concentration

283 was investigated, which could be an introduction to further studies. To learn about the regulation

284 of antioxidative protection, future research on the MnSOD genes is necessary. However, one of

285 the important stages of our experiment was the observation of antioxidative processes due to the

286 re-feeding of animals after the period of starvation, which can lead to the death of half of the

287 population. It should be mentioned that the period of 14 days of starvation and 4, 7, and 14 days

288 of regeneration after returning to feeding were selected in accordance with our previous studies

289 in which the $\mathrm{PNR}_{50}$ for $N$. davidi was presented (Wtodarczyk et al., 2017, 2019). Differences in

290 the values between the hepatopancreas and intestine during fasting are not statistically

291 significant, so it can be concluded that the concentration of free radicals in both organs forming

292 the midgut changes similarly. The results of our research suggest the occurrence of oxidative

293 stress in the first stage of starvation and the activation of anti-ROS defense. In the initial stage of

294 starvation, a rapid increase in the amount of free radicals leads to oxidative stress, which

295 activates the defense mechanism in the form of antioxidant production as has been suggested for

296 other crustaceans (Brouwer et al., 2003; Lin et al. 2010; Gomez-Anduro et al., 2006, 2012; Zhao

297 et al., 2014; Sacristán et al., 2016; Soberanes-Yepiz et al., 2018). After reaching a high level of

298 antioxidants, there is a gradual decrease in the concentration of free radicals caused by re-

299 feeding. Differences in the concentration of free radicals between the hepatopancreas and the

300 intestine after returning to feeding are statistically significant, but they are very small, which

301 indicates that both organs react similarly. Our previous study also describes the effect of 
302 starvation and re-feeding of $N$. davidi on changes in ultrastructure and mitochondrial membrane 303 potentials in hepatopancreatic and intestinal epithelial cells. Mitochondria are organelles which 304 participate not only in ATP production, but also in synthesis of ROS, antioxidative enzymes, cell 305 death activation, etc. (Fernandez-Checa, 2003; Faron et al., 2015; Małota et al., 2019). 306 Additionally, these organelles can contain up to twelve sources of $\mathrm{O}_{2} \bullet-/ \mathrm{H}_{2} \mathrm{O}_{2}$ (Mailloux, 2018).

307 The first signal of changes appearing in the mitochondria is the alteration in the transmembrane 308 mitochondrial potential $(\Delta \mathrm{Cm})$ (Faron et al., 2015; Sonakowska et al. 2016). Ultrastructural 309 alterations together with transmembrane potential $(\Delta \mathrm{Cm})$ may be connected with the activation 310 of cell death (Sonakowska et al., 2010). We reported that starvation activates the degeneration of 311 epithelial cells in $N$. davidi at the ultrastructural level and it causes an increase of cells with 312 depolarized (non-active) mitochondria, while after re-feeding the mitochondria were regenerated 313 at the ultrastructural level and the number of cells with active (polarized) mitochondria increased 314 (Włodarczyk et al., 2017). Comparing the results of ROS activation and mitochondria 315 degeneration, we can state that the increase in free radicals occurs together with a decreasing 316 number of active mitochondria. The number of mitochondria with altered membrane potential 317 also reaches a maximum after a period of 2 weeks of fasting (Wtodarczyk et al., 2017). After re318 feeding the shrimps, a decrease in the level of free radicals was observed as well as an increase 319 in mitochondrial activity in the hepatopancreas and intestine. This may indicate an increase in 320 electron leakage while reducing the mitochondrial membrane potential. Thus, increasing the 321 production of free radicals does not have to be associated with greater mitochondrial activity 322 (Speakman et al., 2004; Faron et al., 2015).

Depending on the level of ROS in the cell, different processes may proceed. At a low ROS level, the cell remains in a quiescent state, not dividing, and not differentiating. The 
325 increase in the level of ROS causes the beginning of proliferation, differentiation or even cell

326 death. Therefore, the level of ROS in cells determines the maintenance of tissue homeostasis and

327 repair of damaged tissues (Zhou et al., 2014). Research in recent years (Karpeta-Kaczmarek et

328 al., 2016; Dziewięcka et al., 2017) has shown the relationship between free radicals and cell

329 death. Free radicals are an important element of signaling pathways of cell death processes.

330 Oxidation of various chemical compounds by ROS leads to the release of e.g. cytochrome $\mathrm{c}$ from

331 mitochondria, which is a signal that triggers apoptosis (Lobo et al., 2010; Kaminskyy and

332 Zhivotovsky, 2014). Excessive concentration of ROS, in turn, causes oxidation of lipids,

333 impairing the functioning of mitochondria, and decreases in ATP concentration, consequently

334 causing necrosis. Cell death can also be activated by the first product of deactivation of

335 superoxide ions, i.e. hydrogen peroxide $\left(\mathrm{H}_{2} \mathrm{O}_{2}\right)$. If the enzymatic protection of the cell against

$336 \mathrm{H}_{2} \mathrm{O}_{2}$ does not work, the Fenton reaction leads to the formation of toxic hydroxyl radicals $(\mathrm{OH})$,

337 against which the cell cannot defend itself. Hydroxyl radicals oxidize lipids in the membranes of

338 various organelles, causing DNA damage and ultimately leading to apoptosis or necrosis (Chen

339 et al., 2009; Redza-Dutordoir et al., 2016). The relationship between the concentration of free

340 radicals and cell death has been described in many organs of crustaceans (Menze et al., 2010;

341 Wang et al., 2013) and it has also been presented due to an experiment that was carried out

342 aimed at studies of the intensity of apoptosis during fasting and re-feeding (Wtodarczyk et al.,

343 2019). After two weeks of fasting, the intensity of apoptosis in the hepatopancreas and the

344 intestine increases almost twofold, while after returning to feeding, regeneration takes place, so

345 the intensity of apoptosis decreases. Two weeks after re-feeding, the intensity of apoptosis is

346 close to zero. The excess of free radicals produced induces apoptosis, the maximum of which is

347 for two weeks of starvation. During this time, the highest level of free radicals is also observed 
$348(13.2,12.7 \%$ for the hepatopancreas and the intestine, respectively). However, the decrease in

349 the intensity of apoptosis to the level of 0 after two weeks from the return to feeding is 350 particularly interesting (Włodarczyk et al., 2019). This correlates with a decrease in ROS from $351 \quad 13.2$ and $12.7 \%$ to 4.2 and $2 \%$ for the hepatopancreas and intestine, respectively, two weeks after 352 re-feeding. Suspension of apoptosis after the regeneration period can be explained by the 353 excessive level of antioxidants, which show a delay in relation to changes in free radical 354 concentrations. The correlation between a high concentration of free radicals and the intensity of 355 apoptosis is greater in the case of the intestine. In the case of the hepatopancreas, a significant 356 increase in the amount of free radicals induces apoptosis to a lesser extent. It can be assumed that 357 the hepatopancreas is the organ that has developed better defenses against free radicals (Borković 358 et al., 2008; Goda, 200; Méndez-Martínez et al., 2018; Soberanes-Yepiz et al., 2018). However, 359 in crustaceans total SOD activities were lower in this organ in comparison to gills and muscle 360 (Borković et al., 2008).

361 Oxidative stress, and therefore the imbalance between ROS and antioxidants, has serious

362 363

364

365

366

367 368 consequences for organisms. Free radicals as highly reactive compounds can cause DNA mutations and damage to genes responsible for the production of antioxidant proteins (Bagchi and Puri, 1998 Hensley et al., 2000; Golden et al., 2002; Faron et al., 2015). As a result, cells that are subjected to long-term oxidative stress can lose their defense against free radicals over time, by impairing the production of antioxidants. Superoxide dismutases (SODs) are enzymes which are responsible for the breakdown of the superoxide anion into oxygen and hydrogen peroxide.

It has been shown that starving shrimps causes a significant increase in the level of free radicals and a subsequent defense response in the form of an increase in the amount of antioxidants - 
371 here MnSOD. This means that the cells are subjected to strong oxidative stress, especially

372 through the initial fasting period. The fasting can thus affect the impairment of the defense

373 system against free radicals, and thus have adverse long-term effects. Regeneration after feeding

374 starved shrimp can therefore be apparent because it does not take into account the irreversible

375 changes that could have occurred in the cell's DNA.

376

377 Conclusions

378 Studies on $N$. davidi shrimp have shown that: (a) long-term starvation increases the concentration

379 of free radicals and MnSOD concentration in the intestine and hepatopancreas; (b) return to

380 feeding causes a decrease in free radicals and in the concentration of MnSOD in the intestine and

381 hepatopancreatic; (c) a distinct relationship between MnSOD concentration, ROS activation, cell

382 death activation and changes in the mitochondrial membrane potential can be observed.

384 References

385 Bagchi K, Puri S. 1998. Free radicals and antioxidants in health and disease. East Mediterranean 386 Health Journal 4(2):350-360.

387 Banniste J, Bannister W, Rotilio G. 1987. Aspects of the structure, function, and applications of 388 superoxide dismutase. Critical Reviews in Biochemistry 22:111-80

389 Borković SS, Pavlović SZ, Kovacević TB, Stajn AS, Petrović VM, Saicić ZS. 2008. Antioxidant 390 defence enzyme activities in hepatopancreas, gills and muscle of Spiny cheek crayfish 391 (Orconectes limosus) from the River Danube. Comparative Biochemistry and Physiology - Part 392 C Toxicology and Pharmacology 147(1):122-8 
393 Bradford MM. 1976. A rapid and sensitive method for the quantitation of microgram quantities

394 of protein utilizing the principle of protein-dye binding. Analitical Biochemistry 72:248-254

395 Brouwer M, Hoexum BT, Grater W, Brown-Peterson N. 2003. Replacement of a cytosolic 396 copper/zinc superoxide dismutase by a novel cytosolic manganese superoxide dismutase in 397 crustaceans that use copper (haemocyanin) for oxygen transport. Biochemical Journal 374:219$398 \quad 228$

399 Cadenas E, Davies KJA. 2000. Mitochondrial free radical generation, oxidative stress, and aging. 400 Free Radical Biology and Medicine 29(3-4):222-230

401 Cao X, Antonyuk SV, Seetharaman SV, Whitson LJ, Taylor AB, Holloway SP, Strange RW, 402 Doucette PA, Valentine JS, Tiwari A, Hayward LJ, Padua S, Cohlberg JA, Hasnain SS, Hart PJ. 403 2008. Structures of the G85R variant of SOD1 in familial amyotrophic lateral sclerosis. The 404 Journal of Biological Chemistry 283:16169-77

405 Cervellione F, McGurk C, Van Den Broeck W. 2017. Effect of starvation and refeeding on the 406 ultrastructure of the perigastric organ (hepatopancreas) in the whiteleg shrimp Litopenaeus 407 vannamei (Boone, 1931) (Decapoda: Caridea: Penaeidae). Journal of Crustacean Biology $408 \quad 37(6): 693-700$

409 Chen Y, Azad MB, Gibson SB. 2009. Superoxide is the major reactive oxygen species regulating 410 autophagy. Cell Death \& Differentiation 16(7):1040-1052

411 Combelles CMH, Gupta S. 2009. Could oxidative stress influence the in-vitro maturation of 412 oocytes? Reproductive BioMedicine Online 18(6):864-880

413 Dziewięcka M, Karpeta-Kaczmarek J, Augustyniak M, Rost-Roszkowska M. 2017. Short-term in 414 vivo exposure to graphene oxide can cause damage to the gut and testis. Journal of Hazardous 415 Materials 328:80-89 
416 Faron J, Bernaś T, Sas-Nowosielska H, Klag J. 2015. Analysis of the Behavior of Mitochondria

417 in the Ovaries of the Earthworm Dendrobaena veneta Rosa. PLoS ONE 10(2):0117187

418 Fernández-Checa JC. 2003. Redox regulation and signaling lipids in mitochondrial apoptosis.

419 BRC Biochemical and Biophysical Research Communications 304(3):471-479

420 Fridovich I. 1995. Superoxide radical and superoxide dismutases. Annual Review of

421 Biochemistry 64:97-112

422 Goda AMAS. 2008. Effect of dietary protein and lipid levels and protein-energy ratio on growth

423 indices feed utilization and body composition of freshwater prawn, Macrobrachium rosenbergii

424 (de Man, 1879) postlar-vae. Aquaculture Research 39:891-901

425 Golden TR, Hinerfeld DA, Melov S. 2002. Oxidative stress and aging: beyond correlation. Aging 426 Cell 1(2):117-123

427 Gómez-Anduro GA, Ascencio-Valle F, Peregrino-Uriarte AB, Cámpa-Córdova A, Yepiz428 Plascencia G. 2012. Cytosolic manganese superoxide dismutase genes from the white shrimp 429 Litopenaeus vannamei are differentially expressed in response to lipopolysaccharides, white spot 430 virus and during ontogeny. Comparative Biochemistry and Physiology, Part B, 162(4):120-5

431 Haque MN, Lee DH, Kim BM, Nam SE, Rhee JS. 2018. Dose- and age-specific antioxidant 432 responses of the mysid crustacean Neomysis awatschensis to metal exposure. Aquatic Toxicology $433 \quad 201: 21-30$

434 Hensley K, Robinson KA, Gabbita SP, Salsman S, Floyd RA. 2000. Reactive oxygen species cell 435 signaling and cell injury. Free Radical Biolology \& Medicine 28(10):1456-1462

436 Herrera - Álvarez L, Fernández I, Benito J, F. 2000. Ultrastructure of the midgut and hindgut of 437 Derocheilocaris remanei (Crustacea, Mystacocarida). Journal of Morphology 244:177-189

438 Kaminskyy VO and Zhivotovsky B. 2014. Free radicals in cross talk between autophagy and 439 apoptosis. Antioxidants \& Redox Signaling 21(1):86-102 
440 Kamogashira T, Fujimoto C, Yamaosba T. 2015. Reactive oxygen species, apoptosis, and 441 mitochondrial dysfunction in hearing loss. BioMed Research International 2015:1-7

442 Karpeta-Kaczmarek J, Dziewięcka M, Augustyniak M, Rost-Roszkowska M, Pawlyta M. 2016. 443 Oxidative stress and genotoxic effects of diamond nanoparticles. Environmental Research $444 \quad 148: 264-272$

445 Lin YC, Lee FF, Wu CL, Chen JC. 2010. Molecular cloning and characterization of a cytosolic 446 manganese superoxide dismutase (cytMnSOD) and mitochondrial manganese superoxide 447 dismutase (mtMnSOD) from the kuruma shrimp Marsupenaeus japonicus. Fish and Shellfish 448 Immunology 28:143-150

449 Lipovšek S, Novak T. 2015. Autophagy in the fat body cells of the cave cricket Troglophilus 450 neglectus Krauss, 1878 (Rhaphidophoridae, Saltatoria) during overwintering. Protoplasma $451 \quad 253(2): 457-66$

452 Lipovšek S, Novak T, Janžekovič F, Leitinger G. 2015. Changes in the midgut diverticula in the 453 harvestmen Amilenus aurantiacus (Phalangiidae, Opiliones) during winter diapause. Arthropod 454 Structure and Development 44(2):131-41

455 Lipovšek S, Leitinger G, Novak T, Janžekovič F, Gorgoń S, Kamińska K, Rost-Roszkowska M. 456 2018. Changes in the midgut cells in the European cave spider, Meta menardi, during starvation 457 in spring and autumn. Histochemistry and Cell Biology 149(93):245-260

458 Lobo V, Patil A, Phatak A, Chandra N. 2010. Free radicals, antioxidants and functional foods:

459 Impact on human health. Pharmacognosy Reviews 4(8):118-126

460 Mailloux RJ. 2018. Mitochondrial antioxidants and the maintenance of cellular

461 hydrogen reroxide levels. Oxidative Medicine and Cellular Longevity 462 https://doi.org/10.1155/2018/7857251 
463 Malota K, Student S, Świątek P. 2019. Low mitochondrial activity within developing earthworm 464 male germ-line cysts revealed by JC-1. Mitochondrion 465 https://doi.org/10.1016/j.mito.2018.01.007

466 Martin LJ. 2010. Mitochondrial and Cell Death Mechanisms in Neurodegenerative Diseases. 467 Pharmaceuticals3:839-915

468 Méndez-Martínez Y, García-Guerrero MU, Arcos-Ortega FG, Martínez-Córdova LR, 469 Yamasaki-Granados S, Pérez-Rodríguez JC, Cortés-Jacinto E. 2018b. Effect of different ratios of 470 dietary protein-energy on growth, body proximal composition, digestive enzyme activity, and 471 hepatopancreas histology in Macrobrachium americanum (Bate, 1868) prawn juveniles. 472 Aquaculture 485: 1-11.

473 Menze MA, Fortner G, Nag S, Hand S.C. 2010. Mechanisms of apoptosis in Crustacea: what 474 conditions induce versus suppress cell death? Apoptosis 15:293-312

475 Mohana K, Padmanaban AM, Uthayakumara V, Chandirasekar R, Muralisankar T, Santhanam 476 R. 2016. Effect of dietary Ganoderma lucidum polysaccharides on biological and physiological 477 responses of the giant freshwater prawn Macrobrachium rosenbergii. Aquaculture 464: 42-49

478 Oropesa AL, Floro AM, Palma P. 2017. Toxic potential of the emerging contaminant nicotine to 479 the aquatic ecosystem. Environmental Science and Pollution Research 24(20):16605-16616 480 Pantaleão JAF, Barros-Alves S, Tropea C, Alves DFR, Negreiros-Fransozo ML, López-Greco 481 LS. 2015. Nutritional vulnerability in early stages of the freshwater ornamental "red cherry 482 shrimp" Neocaridina davidi (Bouvier, 1904) (Caridea: Atyidae). Journal of Crustacean Biology $483 \quad 35(5): 676-681$ 
484 Ramalho-Santos J, Varum S, Sandra Amaral, MotaPC, Sousa AP, Amaral A. 2009. 485 Mitochondrial functionality in reproduction: from gonads and gametes to embryos and 486 embryonic stem cells. Human Reproduction Update 15(5):553-572

487 Ratcliffe NA, King PE. 1969. Morphological, ultrastructural, histochemical and electrophoretic 488 studies on the venom system of Nasonia vitripennis walker (hymenoptera: Pteromalidae). 489 Journal of Morphology 127:177-203

490 Redza-Dutordoir M, Averill-Bates DA. 2016. Activation of apoptosis signalling pathways by 491 reactive oxygen species Maureen. Biochimica et Biophysica Acta (BBA) - Molecular Cell 492 Research 1863(12):2977-2992

493 Rost-Roszkowska MM, Janelt K, Poprawa I. 2018. The role of autophagy in the midgut 494 epithelium of Parachela (Tardigrada). Zoomorphology 137(4):501-509

495 Sacristán HJ, Nolasco-Soria H, López Greco LS. 2014. Effect of attractant stimuli, starvation 496 period, and food availability on digestive enzymes in the redclaw crayfish Cherax 497 quadricarinatus (Parastacidae). Aquatic Biology 23:87-99

498 Sacristán HJ, Ansaldo M, Franco-Tadic LM, Fernández Gimenez AV, López Greco LS. 2016. 499 Long-term starvation and posterior feeding effects on biochemical and physiological responses 500 of midgut gland of Cherax quadricarinatus juveniles (Parastacidae). PLoS ONE 11(3): e0150854 501 Soberanes-Yepiz ML, Méndez-Martínez Y, García-Guerrero MU, Ascencio F, Violante502 González J, García-Ibañez S, Cortés-Jacinto E. 2018. Superoxide dismutase activity in tissues of 503 juvenile cauque river prawn (Macrobrachium americanum Bate, 1868) fed with different 504 levels of protein and lipid. Latin American Journal of Aquatic Research 46(3):543-555 
505 Sonakowska L, Włodarczyk A, Wilczek G, Wilczek P, Student S, Rost-Roszkowska MM. 2016.

506 Cell death in the epithelia of the intestine and hepatopancreas in Neocaridina heteropoda

507 (Crustacea, Malacostraca). PLos ONE 11(2):0147582

508 Sonakowska L, Włodarczyk A, Poprawa I, Binkowski M, Śróbka J, Kamińska K, Kszuk-

509 Jendrysik M, Chajec Ł, Zajusz B, Maria Rost-Roszkowska M. 2015. Structure and ultrastructure

510 of the endodermal region of the alimentary tract in the freshwater shrimp Neocaridina

511 heteropoda (Crustacea, Malacostraca). PLoS ONE 10(5):0126900

512 Sousa L, Petriella AM. 2006. Morphology and histology of $P$. argentinus (Crustacea,

513 Decapoda,Caridea) digestive tract. BIOCELL 30(2):287-294

514 Speakman JR, Talbot DA, Selman C, Snart S, McLaren JS, Redman P, Krol E, Jackson DM,

515 Johnson MS, Brand MD. 2004. Uncoupled and surviving: Individual mice with high metabolism

516 have greater mitochondrial uncoupling and live longer. Aging Cell 3:87-95

517 Umasuthan N, Bathige SD, Revathy KS, Lee Y, Whang I, Choi CY, Park HC, Lee J. 2012. A

518 manganese superoxide dismutase (MnSOD) from Ruditapes philippinarum: comparative

519 structural- and expressional-analysis with copper/zinc superoxide dismutase $(\mathrm{Cu} / \mathrm{ZnSOD})$ and

520 biochemical analysis of its antioxidant activities. Fish and Shellfish Immunology 33(4):753-65.

521 Wang J, Zhang P, Shen Q, Wang Q, Liu D, Li J Wang, L. 2013. The effects of cadmium

522 exposure on the oxidative state and cell death in the gill of freshwater crab Sinopotamon 523 henanense. PLoS One 8, e64020

524 Wilczek G,Rost-Roszkowska M.Wilczek P, A.Babczyńska A, ,E.Szulińska E, L.Sonakowska L, 525 Marek-Swędzioł M. 2014. Apoptotic and necrotic changes in the midgut glands of the wolf 526 spider Xerolycosa nemoralis (Lycosidae) in response to starvation and dimethoate exposure.

527 Ecotoxicology and Environmental Safety 101:157-167 
528 Włodarczyk A, Sonakowska L, Kamińska K, Marchewka A, Wilczek G, Wilczek P, Student S, 529 Rost-Roszkowska M. 2017. The effect of starvation and re-feeding on mitochondrial potential in 530 the midgut of Neocaridina davidi (Crustacea, Malacostraca). PLoS ONE 12(3):0173563

531 Włodarczyk A, Student S, Rost-Roszkowska MM, 2019. Autophagy and apoptosis in starved and 532 re-fed Neocaridina davidi (Crustacea, Malacostraca) midgut. Canadian Journal of Zoology 533 97(4): 294-303

534 Yao CL, Wang AL, Wang WN, SUN RY. 2004. Purification and partial characterization of Mn 535 superoxide dismutase from muscle tissue of the shrimp Macrobrachium nipponense. 536 Aquaculture 241:621-631.

537 Yao CL, Wang AL, Wang ZY, Wang WN, Sun RY. 2007. Purification and partial 538 characterization of $\mathrm{Cu}, \mathrm{Zn}$ superoxide dismutase from haemolymph of oriental river shrimp, 539 Macrobrachium nipponense. Aquaculture 270:559- 565.

540 Yu Z, He X, Fu D and Zhang Y. 2011. Two superoxide dismutase (SOD) with different 541 subcellular localizations involved in innate immunity in Crassostrea hongkongensis. Fish and 542 Shellfish Immunology 31:533-539

543 Zelko IN, Mariani TJ, Folz RJ. 2002. Superoxide dismutase multigene family: a comparison of 544 the CuZn-SOD (SOD1), Mn-SOD (SOD2), and EC-SOD (SOD3) gene structures, evolution, and 545 expression. Free Radical Biology and Medicine 33(3):337-49

546 Zhang QL, Li FH, Wanf B, Zhang JQ, Liu YC, Zhou Q, Xiang JH. 2007. The mitochondrial 547 manganese superoxide dismutase gene in Chinese shrimp Fenneropenaeus chinensis: Cloning, 548 distribution and expression. Developmental and Comparative Immunology 31:429-440 
549 Zhao DX, Chen LQ, Qin JG, Qin CJ, Zhang H, Wu P, Li EC. 2014. Molecular characterization 550 of a cytosolic manganese superoxide dismutase from the Chinese mitten crab, Eriocheir sinensis. 551 Genetics and Molecular Research 13(4):9429-9442.

552 Zhou D, Shao L, Spitz DR. 2014. Reactive oxygen species in normal and tumor stem cells. 553 Advances in Cancer Research 122:1-67. 
555

556 Table legends

557 Table 1. Number of adult specimens of $N$. davidi used in the each part of the experiment.

558

559

560

561

562

\section{Figure legend}

564

565

566

567

568

569

570

571

572

573

574 ROS-positive cells (red), nuclei (n, blue). Confocal microscope. (A) hepatopancreas in animals 575 re-fed for 14 days after 14 days of starvation. Scale bar $=20 \mu \mathrm{M}$. (B) intestine in animals re-fed 576 for 14 days after 14 days of starvation. Scale bar $=20 \mu \mathrm{M}$.

Table 2. Mean (x) \pm standard deviation (SD) of cells with signs of DHE in the entire intestine and proximal zone of hepatopancreatic epithelium in $N$. davidi. The different letters (a, b) denote significant differences between organs within the complementary groups (Student t-test, $p<0.05$; $\mathrm{n}=5)$.

Figure 1. 3D representation of the DHE staining and DAPI staining of hepatopancreas and intestine. ROS-positive cells (red), nuclei (n, blue). Confocal microscope. (A) a fragment of the hepatopancreas in non-starved animals. Scale bar $=20 \mu \mathrm{M}$. (B) a fragment of the intestine in non-starved animals. Scale bar $=20 \mu \mathrm{M}$. (C) a fragment of the hepatopancreas in animals starved for 14 days. Scale bar $=20 \mu \mathrm{M}$. (D) a fragment of the intestine in animals starved for 14 days. Scale bar $=30 \mu \mathrm{M}$. (E) hepatopancreas in animals re-fed for 4 days after 14 days of starvation. Scale bar $=20 \mu \mathrm{M}$. (F) intestine in animals re-fed for 4 days after 14 days of starvation. Scale bar $=20 \mu \mathrm{M}$. (G) hepatopancreas in animals re-fed for 7 days after 14 days of starvation. Scale bar $=$ $20 \mu \mathrm{M} .(\mathrm{H})$ intestine in animals re-fed for 7 days after 14 days of starvation. Scale bar $=20 \mu \mathrm{M}$.

Figure 2. 3D representation of the DHE and DAPI staining of hepatopancreas and intestine. 
577 Figure 3. Diagrammatic representation of the average percentage of ROS-positive cells during

578 starvation and after re-feeding. Flow cytometry.

579 Figure 4. Western blot analysis of Superoxide Dismutase (MnSOD) in the midgut of freshwater 580 shrimp Neocaridina davidi (25 $\mu \mathrm{g}$ of protein per each line).

581 Figure 5. 3D representation of the MnSOD localization (green) and DAPI staining of

582 hepatopancreas and intestine. Nuclei (n, blue). Confocal microscope.

583 (A) a fragment of the hepatopancreas in non-starved animals. Scale bar $=30 \mu \mathrm{M}$. (B) a fragment 584 of the intestine in non-starved animals. Scale bar $=20 \mu \mathrm{M}$. (C) a fragment of the hepatopancreas 585 in animals starved for 14 days. Scale bar $=30 \mu \mathrm{M}$. (D) a fragment of the intestine in animals 586 starved for 14 days. Scale bar $=30 \mu \mathrm{M}$. (E) hepatopancreas in animals re-fed for 4 days after 14 587 days of starvation. Scale bar $=30 \mu \mathrm{M}$. (F) intestine in animals re-fed for 4 days after 14 days of 588 starvation. Scale bar $=20 \mu \mathrm{M}$. (G) hepatopancreas in animals re-fed for 7 days after 14 days of 589 starvation. Scale bar $=30 \mu \mathrm{M}$. (H) intestine in animals re-fed for 7 days after 14 days of 590 starvation. Scale bar $=30 \mu \mathrm{M}$.

591 Figure 6. 3D representation of the MnSOD localization (green) and DAPI staining of 592 hepatopancreas and intestine. Nuclei (n, blue). Confocal microscope.

593 (A) hepatopancreas in animals re-fed for 14 days after 14 days of starvation. Scale bar $=30 \mu \mathrm{M}$.

594 (B) intestine in animals re-fed for 14 days after 14 days of starvation. Scale bar $=20 \mu \mathrm{M}$. 


\section{Table 1 (on next page)}

Number of adult specimens of $N$. davidi used in the each part of the experiment. 


\begin{tabular}{|c|c|c|c|}
\hline \multirow[t]{3}{*}{$\begin{array}{l}\text { Number of days } \\
\text { of starvation }\end{array}$} & \multicolumn{3}{|c|}{$\begin{array}{l}\text { Number of specimens analyzed } \\
\text { Part 1: starvation }\end{array}$} \\
\hline & \multirow{2}{*}{$\begin{array}{c}\text { Flow } \\
\text { cytometry-DHE }\end{array}$} & \multicolumn{2}{|c|}{ Confocal microscopy } \\
\hline & & MnSOD & DHE \\
\hline control & 24 & 4 & 4 \\
\hline 14 days & 24 & 4 & 4 \\
\hline \multirow{3}{*}{$\begin{array}{l}\text { Number of days } \\
\text { of re-feeding } \\
\text { after } 14 \text { days of } \\
\text { starvation }\end{array}$} & \multicolumn{3}{|c|}{$\begin{array}{l}\text { Number of specimens analyzed } \\
\text { Part 2: re-feeding after } 14 \text { days of starvation }\end{array}$} \\
\hline & \multirow[t]{2}{*}{$\begin{array}{c}\text { Flow } \\
\text { cytometry-DHE }\end{array}$} & \multicolumn{2}{|c|}{ Confocal microscopy } \\
\hline & & MnSOD & DHE \\
\hline 4 days & 24 & 4 & 4 \\
\hline 7 days & 24 & 4 & 4 \\
\hline 14 days & 24 & 4 & 4 \\
\hline
\end{tabular}

1

2 Table 1. Number of adult specimens of $N$. davidi used in each part of the experiment. 


\section{Table 2 (on next page)}

Mean $(x) \pm$ standard deviation (SD) of cells with signs of DHE in the entire intestine and proximal zone of hepatopancreatic epithelium in $N$. davidi.

The different letters $(a, b)$ denote significant differences between organs within the complementary groups (Student t-test, $p<0.05 ; \mathrm{n}=5$ ). 


\begin{tabular}{|l|l|l|}
\hline & Hepatopancreas & intestine \\
\hline control group & $2.8 \pm 1.2 \mathrm{a}$ & $1.3 \pm 0.6 \mathrm{a}$ \\
\hline 14 days of starvation & $13.2 \pm 2.1 \mathrm{a}$ & $12.7 \pm 1.2 \mathrm{a}$ \\
\hline $\begin{array}{l}\text { 4 days of re-feeding } \\
\text { after 14 days of starvation }\end{array}$ & $15.7 \pm 4.4 \mathrm{a}$ & $9.2 \pm 4.3 \mathrm{a}$ \\
\hline $\begin{array}{l}\text { 7 days of re-feeding } \\
\text { after 14 days of starvation }\end{array}$ & $5.4 \pm 1.8 \mathrm{~b}$ & $2.0 \pm 0.4 \mathrm{a}$ \\
\hline $\begin{array}{l}\text { 14 days of re-feeding } \\
\text { after 14 days of starvation }\end{array}$ & $4.2 \pm 0.6 \mathrm{~b}$ & $2.0 \pm 0.4 \mathrm{a}$ \\
\hline
\end{tabular}

1

2 Table 2. Mean (x) \pm standard deviation (SD) of cells with signs of DHE in the entire intestine 3 and proximal zone of hepatopancreatic epithelium in $N$. davidi. The different letters (a, b) denote 4 significant differences between organs within the complementary groups (Student t-test, $p<0.05$; $5 \mathrm{n}=5)$. 


\section{Figure 1}

3D representation of the DHE staining and DAPI staining of hepatopancreas and intestine. ROS-positive cells (red), nuclei ( $n$, blue). Confocal microscope.

ROS-positive cells (red), nuclei ( $\mathrm{n}$, blue). Confocal microscope. (A) a fragment of the hepatopancreas in non-starved animals. Scale bar $=20 \mu \mathrm{M}$. (B) a fragment of the intestine in non-starved animals. Scale bar $=20 \mu \mathrm{M}$. (C) a fragment of the hepatopancreas in animals starved for 14 days. Scale bar $=20 \mu \mathrm{M}$. (D) a fragment of the intestine in animals starved for 14 days. Scale bar $=30 \mu \mathrm{M}$. (E) hepatopancreas in animals re-fed for 4 days after 14 days of starvation. Scale bar $=20 \mu \mathrm{M}$. (F) intestine in animals re-fed for 4 days after 14 days of starvation. Scale bar $=20 \mu \mathrm{M}$. (G) hepatopancreas in animals re-fed for 7 days after 14 days of starvation. Scale bar $=20 \mu \mathrm{M}$. $(\mathrm{H})$ intestine in animals re-fed for 7 days after 14 days of starvation. Scale bar $=20 \mu \mathrm{M}$. 

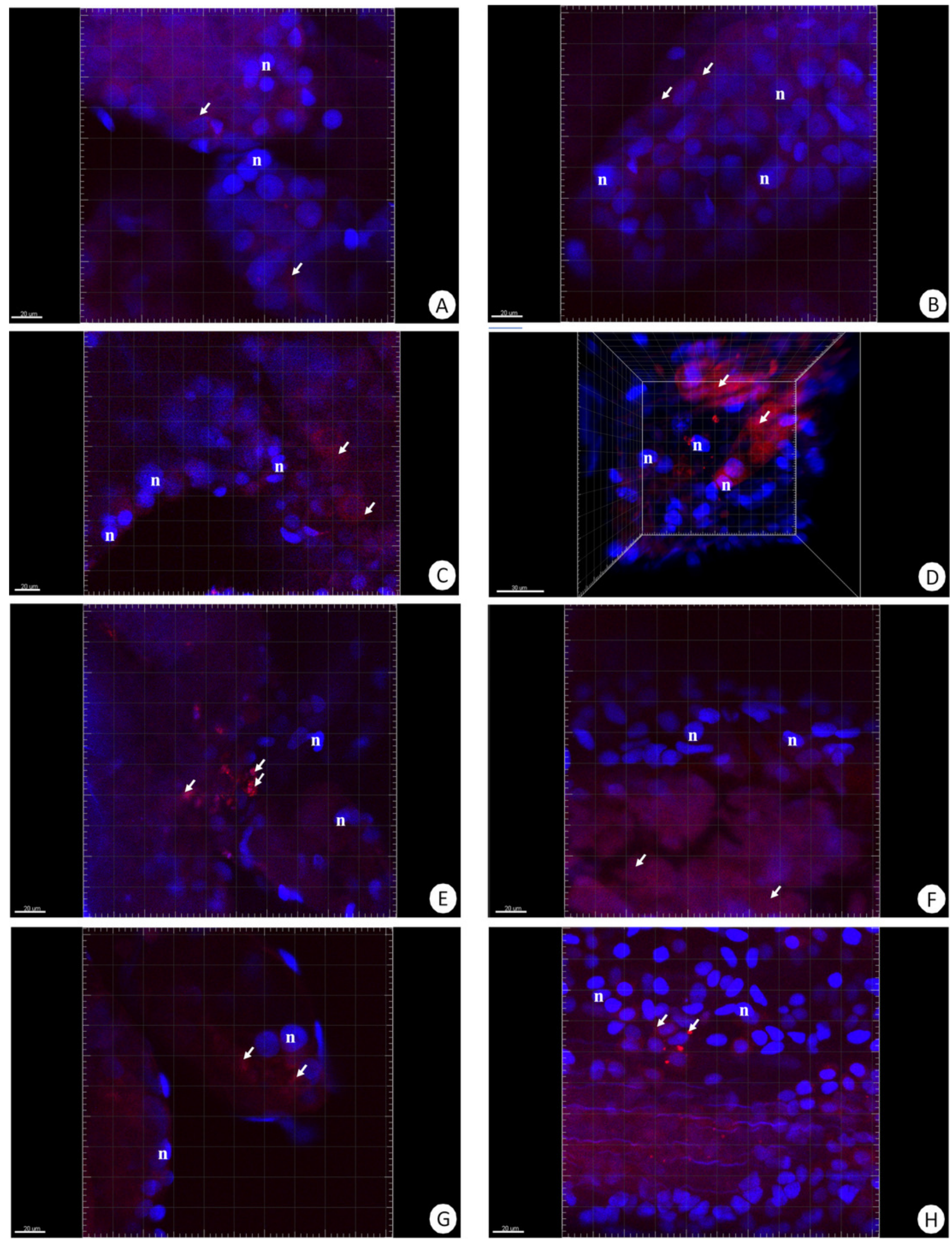

$\Theta$

Peer) reviewing PDF | (2019:03:36053:1:1:REVIEW 19 Jun 2019) 


\section{Figure 2}

3D representation of the DHE and DAPI staining of hepatopancreas and intestine. ROSpositive cells (red), nuclei ( $n$, blue). Confocal microscope.

(A) hepatopancreas in animals re-fed for 14 days after 14 days of starvation. Scale bar $=20$ $\mu \mathrm{M}$. (B) intestine in animals re-fed for 14 days after 14 days of starvation. Scale bar $=20 \mu \mathrm{M}$.
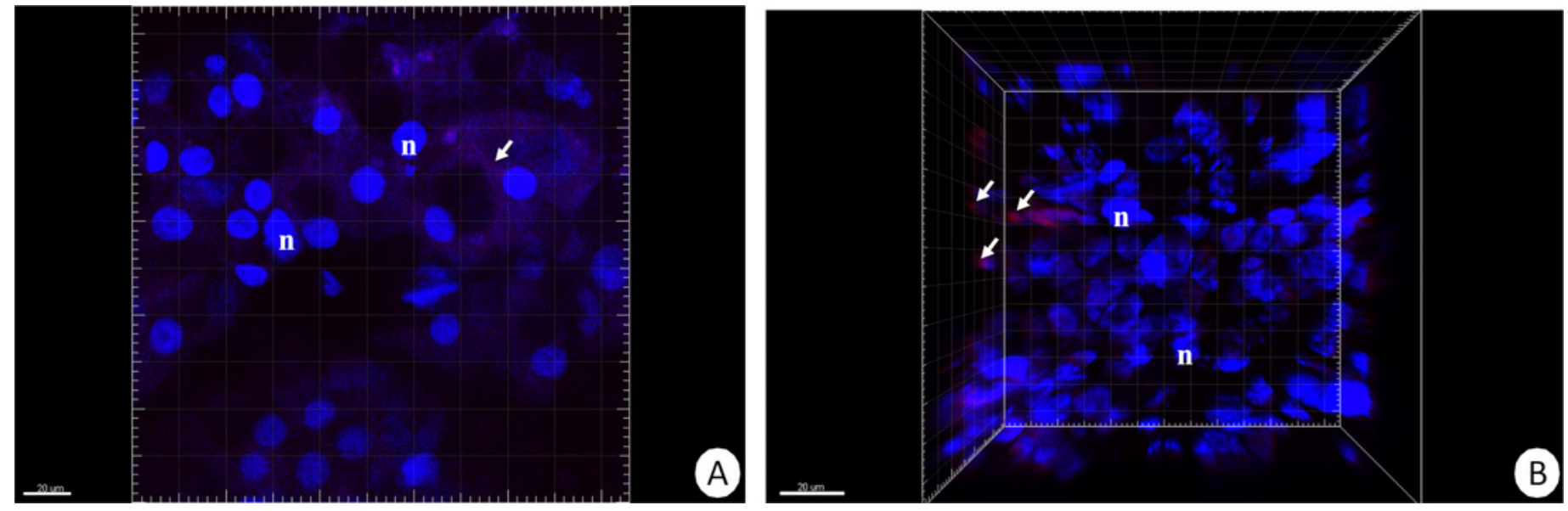
Figure 3

Diagrammatic representation of the average percentage of ROS-positive cells during starvation and after re-feeding. Flow cytometry.

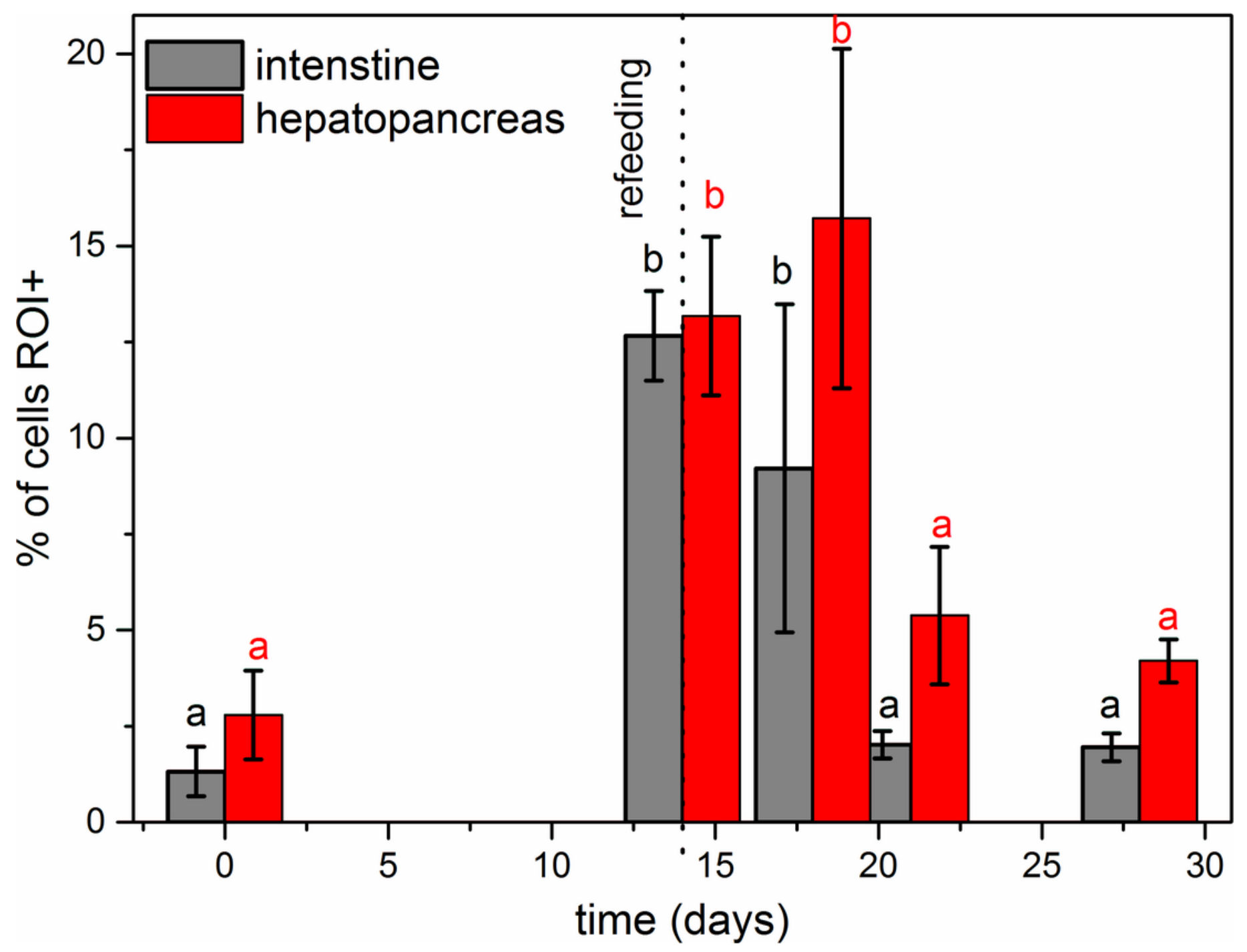


Figure 4

Western blot analysis of Superoxide Dismutase (MnSOD) in the midgut of freshwater shrimp Neocaridina davidi (25 $\mu \mathrm{g}$ of protein per each line). 


\section{Figure 5}

$3 \mathrm{D}$ representation of the MnSOD localization (green) and DAPI staining of hepatopancreas and intestine. Nuclei ( $n$, blue). Confocal microscope.

(A) a fragment of the hepatopancreas in non-starved animals. Scale bar $=30 \mu \mathrm{M}$. (B) a fragment of the intestine in non-starved animals. Scale bar $=20 \mu \mathrm{M}$. (C) a fragment of the hepatopancreas in animals starved for 14 days. Scale bar $=30 \mu \mathrm{M}$. (D) a fragment of the intestine in animals starved for 14 days. Scale bar $=30 \mu \mathrm{M}$. (E) hepatopancreas in animals re-fed for 4 days after 14 days of starvation. Scale bar $=30 \mu \mathrm{M}$. (F) intestine in animals refed for 4 days after 14 days of starvation. Scale bar $=20 \mu \mathrm{M}$. (G) hepatopancreas in animals re-fed for 7 days after 14 days of starvation. Scale bar $=30 \mu \mathrm{M} .(\mathrm{H})$ intestine in animals refed for 7 days after 14 days of starvation. Scale bar $=30 \mu \mathrm{M}$. 

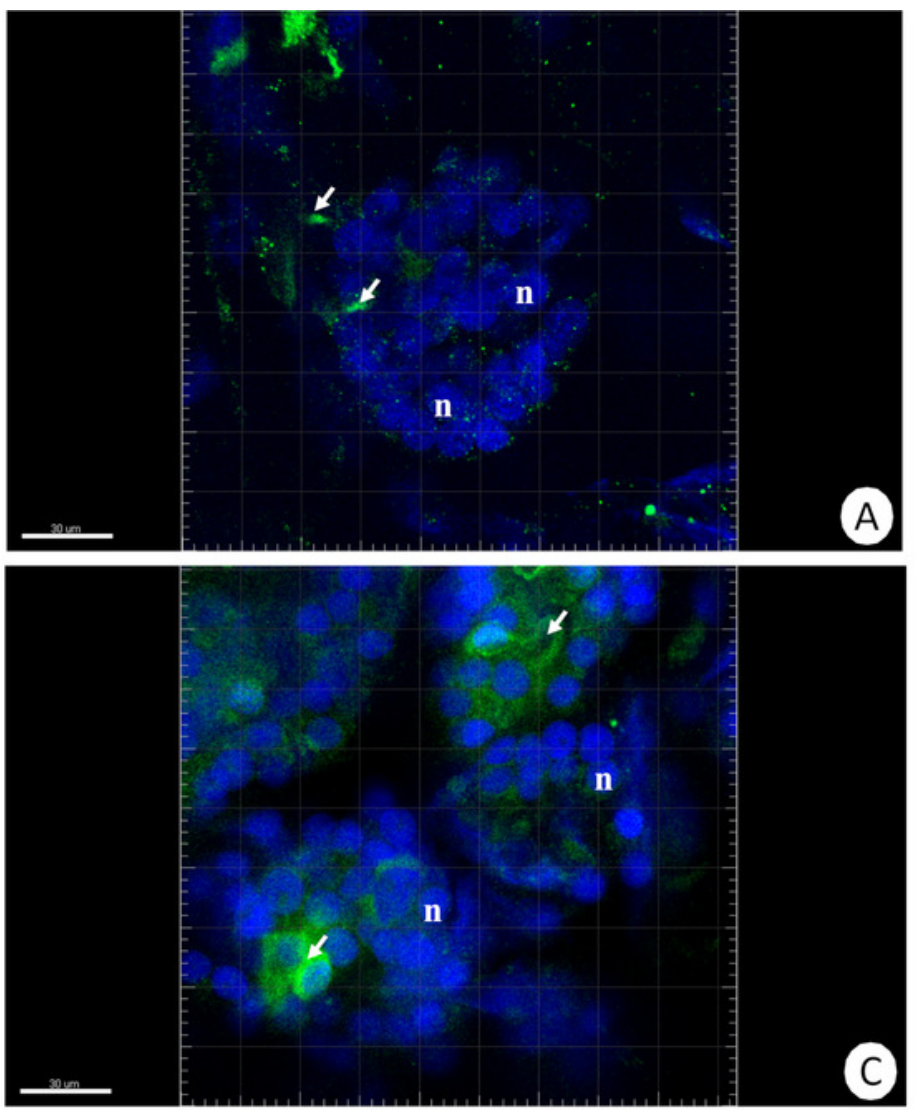

(A)

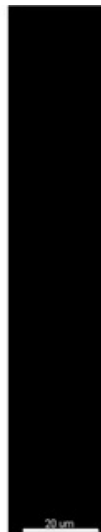

B
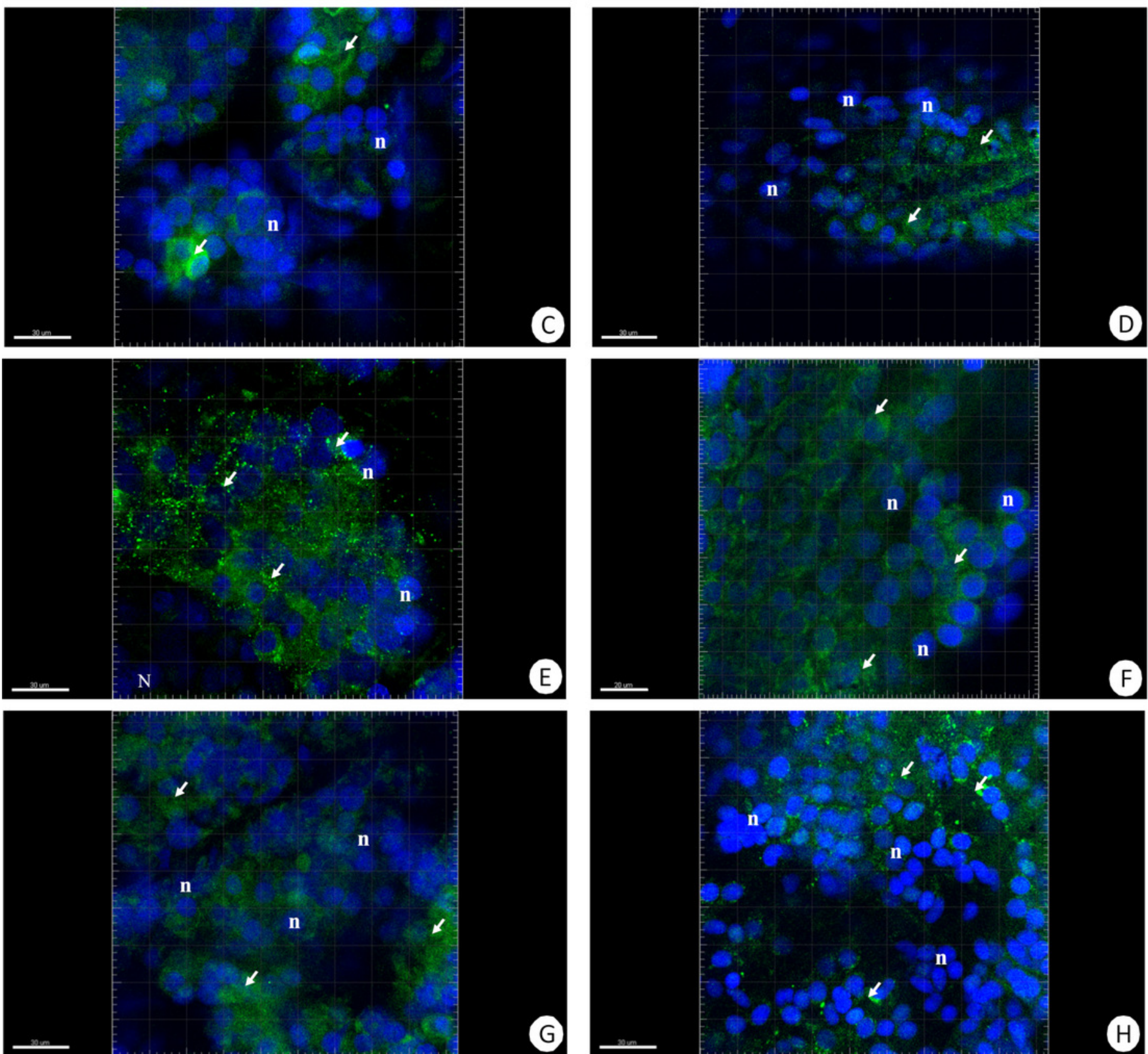

n

n
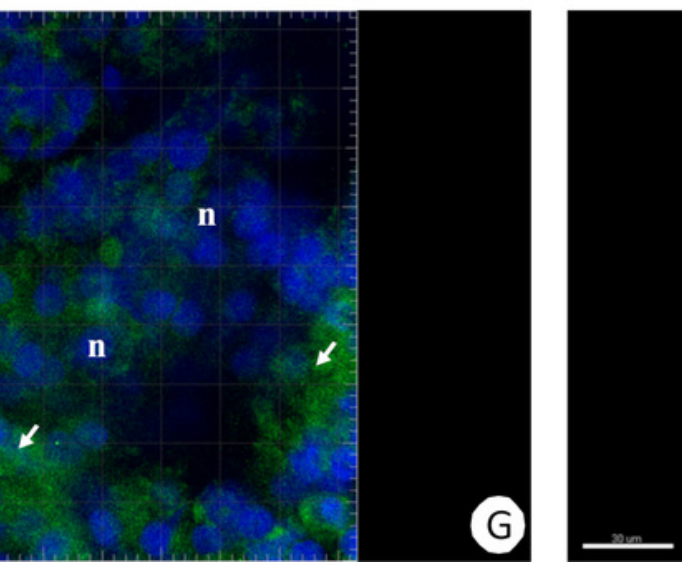

(H) 


\section{Figure 6}

$3 \mathrm{D}$ representation of the MnSOD localization (green) and DAPI staining of hepatopancreas and intestine. Nuclei ( $n$, blue). Confocal microscope.

(A) hepatopancreas in animals re-fed for 14 days after 14 days of starvation. Scale bar $=30$ $\mu \mathrm{M}$. (B) intestine in animals re-fed for 14 days after 14 days of starvation. Scale bar $=20 \mu \mathrm{M}$.
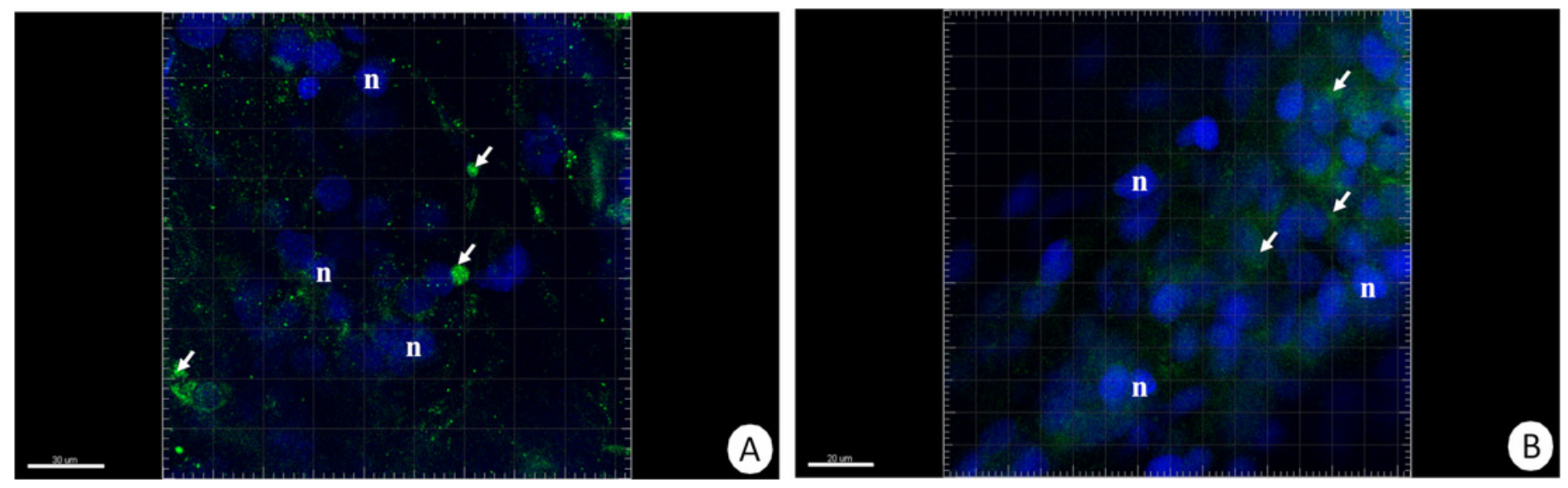